\title{
Potencial de progênies dioicas de mamoeiro para resistência à oídio
}

\author{
Cláudia Roberta Ribeiro de Oliveira ${ }^{1}$, Marcelo Vivas ${ }^{2}$, Silvaldo Felipe da Silveira ${ }^{1}$, Vivane Miriam Lanhellas \\ Gonçalves $^{3}$, Rogério Figeuiredo Dhaer ${ }^{2}$, Geraldo do Amaral Gravina ${ }^{2}$, Messias Gonzaga Pereira ${ }^{3}$
}

\begin{abstract}
${ }^{1}$ Laboratório de Entomologia e Fitopatologia; ${ }^{2}$ Laboratório de Engenharia Agrícola; ${ }^{3}$ Laboratório de Melhoramento Genético Vegetal, Centro de Ciências e Tecnologias Agropecuárias, Universidade Estadual do Norte Fluminense Darcy Ribeiro, Av. Alberto Lamego, 2000 - Parque Califórnia, Campos dos Goytacazes, RJ, Brasil. CEP: 28013-602
\end{abstract}

Autor para correspondência: Marcelo Vivas (mrclvivas@hotmail.com)

Data de chegada: 28/07/2016. Aceito para publicação em: 26/06/2018.

$10.1590 / 0100-5405 / 167210$

\section{RESUMO}

Oliveira, C.R.R.; Vivas, M.; Silveira, S.F.; Gonçalves, V.M.L.; Dhaer, R.F.; Gravina, G.A.; Pereira, M.G. Potencial de progênies dioicas de mamoeiro para resistência à oídio. Summa Phytopathologica, v.44, n.4, p.350-354, 2018.

Variedades crioulas constituem fontes importantes de variabilidade genética a ser explorada pelos programas de melhoramento de plantas. No Brasil, o mamoeiro é cultivado comercialmente principalmente nos estados do Espírito Santo e Bahia, mas, domesticamente, é cultivado em todo extenso território brasileiro. Entretanto, estudos de exploração da variabilidade genética existente em variedades dióicas de mamoeiro são incipientes no País. O objetivo desse trabalho foi avaliar o potencial de 20 genótipos dióicos de mamoeiro para características relacionadas à resistência à oídio (Streptopodium caricae). Para tal, foi conduzido experimento em casa de vegetação delineado em blocos casualizados, com quatro repetições e uma planta por parcela. Avaliaram-se: incidência de folhas com sintoma de oídio e a severidade de oídio na quinta e sétima folhas. Os dados obtidos foram submetidos a análise de variância e teste de comparação de médias via método dos quadrados mínimos. Também foram estimados os componentes de variância e o valor genético de progênies para incidência e severidade de oídio via modelos mistos. Observou-se uma situação favorável para se praticar seleção visando à resistência a oídio, com herdabilidade variando de 51,57 à 67,82 e acurácia seletiva acima de $70 \%$. As progênies PMI1, PMI6, PMI8, PMI11, PMI12 e PMI15 foram as que se destacaram por apresentarem potencial para redução tanto da incidência quanto da severidade de oídio em folha.

Palavras-chave: Carioca papaya; Streptopodium caricae; genótipos crioulos; resistência a doença

\section{ABSTRACT}

Oliveira, C.R.R.; Vivas, M.; Silveira, S.F.; Gonçalves, V.M.L.; Dhaer, R.F.; Gravina, G.A.; Pereira, M.G. Potential of dioecious progenies of papaya plants for resistance to powdery mildew. Summa Phytopathologica, v.44, n.4, p.350-354, 2018.

Landraces are important sources of genetic variability to be exploited by plant breeding programs. In Brazil, papaya is commercially grown mainly in the states of Espirito Santo and Bahia but, domestically, it is grown throughout the extensive Brazilian territory. However, exploration studies of genetic variability in local varieties of papaya are incipient in the country. The aim of this study was to evaluate the potential of 20 dioecious papaya genotypes for traits related to resistance to powdery mildew (Streptopodium caricae). Thus, this experiment was conducted in a greenhouse, in randomized block design, with four replicates and one plant per plot. The following were evaluated: incidence of leaves with powdery mildew symptoms and severity of powdery mildew in the fifth and seventh leaves. The obtained data were subjected to analysis of variance and mean comparison test via the least squares method. The variance components and the genetic value of progenies for incidence and severity of powdery mildew were also estimated via mixed models. There was a favorable situation for selection aimed at resistance to powdery mildew, with heritability ranging from 51.57 to 67.82 and selective accuracy above 70\%. PMI1, PMI6, PMI8, PMI11, PMI12 and PMI15 stood out for presenting potential to reduce both the incidence and the severity of powdery mildew on foliage.

Keywords: Carica papaya; Streptopodium caricae; landraces; disease resistance

A cultura do mamoeiro, Carica papaya L., é representada por uma reduzida gama de cultivares comerciais cultivados mundialmente. Essa baixa variabilidade genética da cultura pode ser expressa, também, pela existência de apenas dois grupos heteróticos, que abrangem toda a produção brasileira: "Solo" e "Formosa" (4). Dessa forma, a cultura do mamoeiro também apresenta vulnerabilidade genética para resistir aos ataques de doenças e de pragas, o que compromete a sustentabilidade da produção, sendo a ocorrência de doenças o principal fator responsável por este comprometimento.

Nas regiões produtoras litorâneas do norte capixaba e sul da Bahia, o oídio, causado por Streptopodium caricae Liberato \& R.W. Barreto, é uma doença constante em plantios comerciais (6) e que se agrava no período mais frio e seco do ano. Nestas épocas, é necessário efetuar o controle químico com a aplicação de fungicidas para reduzir os sintomas e os danos causados pelo oídio (17). A doença, nas folhas, provoca amarelecimento, seca e desfolha precoces, reduzindo o vigor da planta e a produção. Na face abaxial das folhas, surgem pontos encharcados, caracterizados pelo micélio e frutificações do patógeno, e em alguns casos há a formação de massa pulverulenta branco-acinzentada (17).

A busca pelo aumento da variabilidade genética na cultura do mamoeiro, por meio do desenvolvimento de novas variedades resistentes ao oídio, pode garantir maior competitividade no comércio de frutos e de sementes produzidas no Brasil, bem como promover a sustentabilidade da cultura, nas áreas de produção e nas regiões onde 
a cultura se encontra atualmente fixada. Neste aspecto, as variedades crioulas, também denominadas de variedades locais ou landraces, podem ser usadas em programas de melhoramento para ampliação da variabilidade genética, com objetivos de seleção de novos materiais e como fontes de genes de adaptação, resistência a estresses bióticos e abióticos, em diversas culturas agrícolas $(1,5,7,8)$.

No Brasil, ênfase a variedades dióicas, tem sido dada pelos programas de melhoramento genético do mamoeiro, na busca da ampliação da base genética dos bancos de germoplasma existentes ( 9 , $10,18,21,22)$. No que tange aos estudos relacionados à resistência a doenças, os trabalhos ainda são incipientes e se restringem a estudos relacionados a pinta-preta [Asperisporium caricae (Speg.) Maubl.] $(18,21)$ e mancha-de-phoma [Stagonosporopsis caricae (Sydow \& P. Sydow) Aveskamp, Gruyter \& Verkley] (22). Entretanto, nada se sabe sobre o potencial de progênies dióicas quanto a resistência a oídio, evidenciando assim, a importância deste trabalho. Os poucos trabalhos com este patossistema se restringe à avaliação de genótipos elite per si (24) e em combinação $(19,23)$. Havendo necessidade de estudos tanto dos níveis de resistência, quanto do potencial das progênies dióicas obtidas.

Além disso, é importante para o melhoramento genético, que os trabalhos de avaliação de resistência a doenças sejam acompanhados de estimativas de parâmetros genéticos que permitam conhecer a estrutura genética da população e a variabilidade genética quanto às características de interesse, de modo a subsidiar a predição dos ganhos genéticos e o sucesso do programa de melhoramento. Essas estimativas também são importantes para: definir e reorientar os métodos de melhoramento a serem utilizados; identificar a natureza e ação dos genes envolvidos no controle dos caracteres quantitativos; definir a eficiência das diferentes estratégias de melhoramento para obtenção de ganhos genéticos e para manter e ampliar da base genética da população (2).

Dado o exposto, objetivou-se neste trabalho identificar genótipos de mamoeiro resistentes à oídio, utilizando-se da abordagem via quadrados mínimos e modelagem mista, a partir de seleção praticada em população dióica, a fim de que os materiais mais promissores sejam inseridos nos programas de melhoramento genético do mamoeiro.

\section{MATERIAL E MÉTODOS}

Instalou-se experimento em delineamentos em blocos casualizados com quatro repetições e uma planta por parcela, em condições de casa de vegetação, no Campus Leonel Brizola da Universidade Estadual Norte Fluminense Darcy Ribeiro. Foram testadas 20 progênies de meiosirmãos de mamoeiro proveniente de seleção prévia feita a partir de genótipos crioulos $(18,21)$. Para fins comparativos também foi incluída no estudo a variedade Maradol, que apresenta padrão de resistência a várias doenças foliares $(18,20,24)$. Os genótipos foram semeados em tubetes de $53 \mathrm{~cm}^{3}$, contendo substrato comercial (Plantimax). Após 60 dias do semeio, as plântulas foram transplantadas para vasos com 10L de capacidade, contendo terra + esterco bovino + areia $(2: 1: 1)$.

Não houve a necessidade de se proceder a inoculação, uma vez que próximo a local de condução do experimento, existiam plantas com sintomas da doença. Foram avaliadas a severidade e incidência do oídio. $\mathrm{Na}$ avaliação da severidade da doença, considerou-se a quinta e a sétima folha, contada a partir do ápice da planta, utilizando-se escala diagramática desenvolvida por Santos et al. (16). A incidência da doença foi obtida relacionando-se o número de folhas com sintoma visual e o número total de folhas por planta.
Com os dados fenotípicos conduziu-se análise de variância, comparação das médias dos genótipos (progênies e testemunha) pelo teste Tukey a $5 \%$ de probabilidade, utilizando o programa Genes (3). Com os mesmos dados fenotípicos, considerando-se apenas as progênies, obteve-se, via software Selegen-Reml/Blup (13), as estimativas dos componentes de variâncias (REML Individual), e foi obtido via BLUP o efeito genético aditivo predito dos genitores, bem como o efeito genético aditivo predito para cada indivíduo, para cada variável. Utilizou-se para tal o modelo: $\mathrm{y}=\mathrm{Xr}+\mathrm{Za}+\mathrm{e}$, em que $\mathbf{y}$ é o vetor de dados; $\mathbf{r}$ é o vetor dos efeitos de repetição (assumidos como fixos) somados à média geral; a é o vetor dos efeitos genéticos aditivos individuais (assumidos como aleatórios); e é o vetor de erros ou resíduos (aleatórios). As letras maiúsculas representam as matrizes de incidência para os referidos efeitos.

\section{RESULTADOS E DISCUSSÃO}

Assim como observado para pinta-preta $(18,21)$ e mancha-dephoma (22), as progênies dióicas obtidas e avaliadas no presente estudo também apresentam potencial para resistência a oídio, haja visto que a análise de variância indicou haver efeito significativo da fonte de variação genótipo $(\mathrm{p}<0,01)$ para as três variáveis testadas. Não por acaso as estimativas de variância genotípica foram superiores a variância ambiental (Figura 1). Observou-se que a estimativa de herdabilidade variou de 51,57 (incidência de oídio) à 67,82 (severidade de oídio avaliada na sétima folha), indicando a possibilidade de sucesso no processo de seleção. Os resultados estão em consonância com os obtidos em outros trabalhos (18). Para resistência à pinta-preta, foram encontradas estimativas moderadas de herdabilidade para severidade de pinta-preta avaliadas em progênies crioulas de mamoeiro (18).

Pelos resultados apresentados, conclui-se haver possibilidade de seleção de progênies de mamoeiro com potencial para a redução da intensidade de oídio. Fato este corroborado pela comparação das médias destas progênies com a testemunha 'Maradol', genótipo tido como padrão de resistência para doenças foliares do mamoeiro (24). Para incidência de folhas com sintoma de oídio, a média variou de 38,9\% (PMI20) a 9,3\% (PMI1). Observa-se que a progênie PMI1, foi a mais resistente, não diferindo estatisticamente das progênies PMI12 e PMI16 (Figura 2A). As três progênies, PMI1, PMI12 e PMI16 foram consideradas de interesse para o programa de melhoramento genético objetivando a resistência ao oídio. Destas progênies, PMI1 e PMI12 se destacaram como fonte de resistência ao oídio, diferindo significativamente da testemunha ('Maradol'), com baixa média de incidência dos sintomas da doença nas folhas. O potencial de genótipo 'Maradol' foi relatado por Vivas et al. (24) para resistência a múltiplas doenças.

A semelhança do observado para incidência, quando se analisou a severidade de oídio em folha, observou-se que a maior amplitude das médias ocorreu para PMI20 e PMI1. Sendo a progênie PMI1, a que apresentou a menor média, nas duas folhas avaliadas, ou seja, na quinta e na sétima folhas (Figura $2 \mathrm{~B}$ e C). Treze progênies apresentaram médias estatisticamente iguais a PMI1: PMI2, PMI3, PMI5, PMI6, PMI7, PMI8, PMI9, PMI11, PMI12, PMI 14, PMI15, PMI 17 e PMI19. Destas progênies, apenas a PMI12, juntamente com PMI1 apresentaram as menores médias de incidência e severidade de oídio em folha, sendo, portanto, as mais promissoras, o que as torna fontes de resistência em potencial no programa de melhoramento do mamoeiro.

Visando conhecer o real potencial das progênies de mamoeiro 


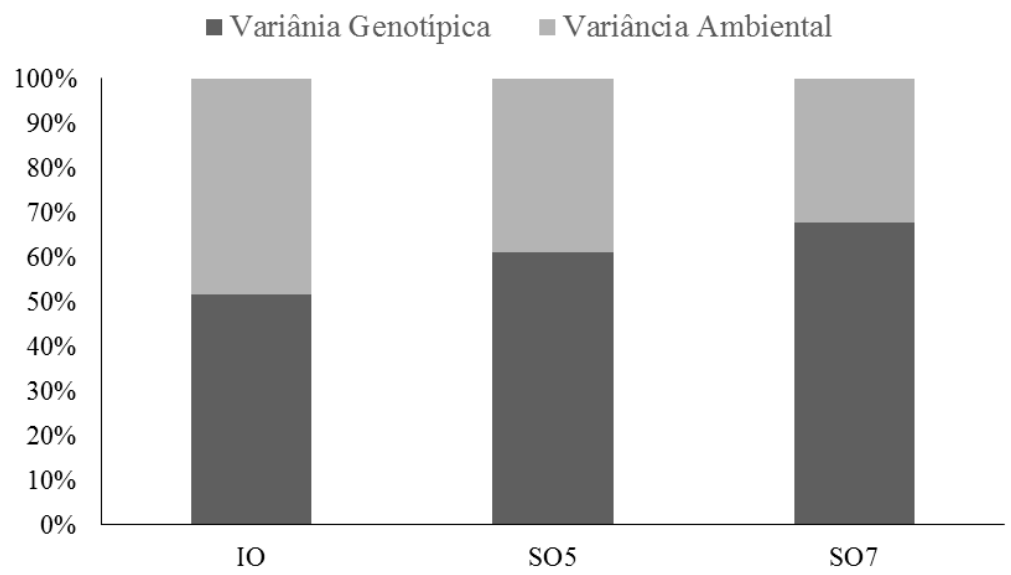

Figura 1. Proporção da variância ambiental (barras claras), da variância genotípica (barra escuras) sobre a variância fenotípica, obtidas para: Incidência de Folhas com sintoma de oídio (IO), Severidade de oídio estimada na quinta (SO5) e sétima folha (SO7).

A

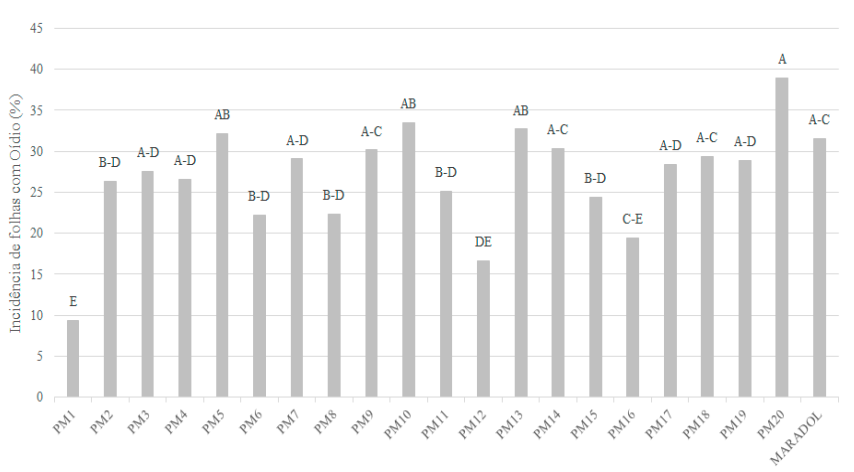

B

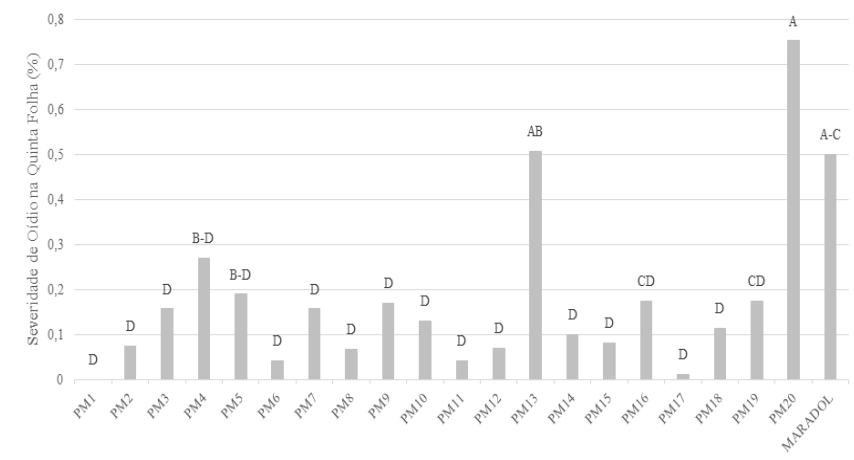

$\mathrm{C}$

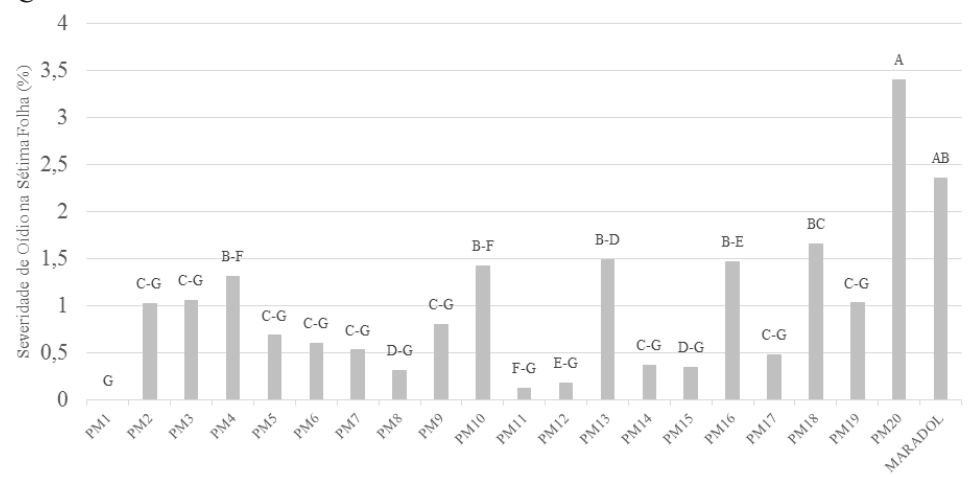

Figura 2. Incidência média de folhas com sintomas de oídio (A), Severidade de oídio estimada na quinta (B) e sétima folha (C), de progênies de meio-irmãos derivados de genótipos dióicos de mamoeiro e do genótipo resistente Maradol. Para uma mesma variável, médias seguidas de mesma letra não difere entre si pelo teste Tukey a 0,05 de probabilidade.

como fontes de resistência a oídio, nova análise foi conduzida considerando apenas as progênies, individualmente, utilizando-se de modelagem mista. Esta abordagem tem sido utilizada com sucesso pelos melhoristas, entretanto, para mamoeiro ela ainda é incipiente, limitando-se a poucos trabalhos $(11,12,22,23)$. Pela análise dos componentes de variância obtidos pela máxima verossimilhança restrita (REML), contatou-se que tanto para incidência de folhas com sintoma de oídio, quanto para severidade de oídio em folha a variância fenotípica foi explicada majoritariamente pela variância aditiva (Tabela 1). Observou-se também que as magnitudes das herdabilidades estimadas com base na média de progênies foram superiores a $50 \%$ para as três variáveis em estudo (Tabela 1), sendo estas mais para as variáveis relacionadas à severidade. Isso demonstra uma situação favorável à seleção de progênies que possam contribuir para a redução de oídio, haja vista que grande parte da variação fenotípica observada é devida ao componente genético.

Referente à qualidade do experimento, Resende (14) afirma que esta deve ser inferida preferencialmente com base na acurácia. $\mathrm{O}$ autor considera ainda que para o processo de seleção em programas de melhoramento, devem ser buscados valores de acurácia acima de $70 \%$. No presente estudo, observou-se para as três variáveis em estudo estimativas superiores a recomendada (Tabela 1). Segundo Resende 
Tabela 1. Estimativas de componentes de variância obtidos para incidência de folha com sintoma de oídio (IO) e severidade de oídio estimada na quinta (SO5) e sétima (SO7) folha, por meio da Máxima Verossimilhança Restrita (REML), Campos dos Goytacazes, 2014.

\begin{tabular}{|c|c|c|c|}
\hline Componentes de variância & IO & SO5 & SO7 \\
\hline Variância genética aditiva & 86,53 & 0,07 & 1,07 \\
\hline Variância residual & 18,83 & 0,00 & 0,00 \\
\hline Variância fenotípica individual & 105,36 & 0,07 & 1,07 \\
\hline Herdabilidade da média das progênies & 0,51 & 0,60 & 0,73 \\
\hline Acurácia da Seleção de progênie & 0,71 & 0,77 & 0,86 \\
\hline Coeficiente de variação genética aditiva individual & 34,88 & 166,38 & 143,87 \\
\hline Coeficiente de variação genética entre progênies & 17,44 & 83,19 & 71,94 \\
\hline Coeficiente de variação residual & 34,31 & 136,53 & 86,93 \\
\hline Coeficiente de variação relativa & 0,51 & 0,61 & 0,83 \\
\hline Variação do erro de predição dos valores genotípicos & 10,64 & 0,01 & 0,12 \\
\hline Desvio padrão do valor genotípico predito & 3,26 & 0,09 & 0,34 \\
\hline Média geral do experimento & 26,67 & 0,16 & 0,92 \\
\hline
\end{tabular}

Tabela 2. Estimativas da contribuição relativa de cada genitor para a formação da próxima geração, obtidas para incidência de folha com sintoma de oídio (IO) e severidade de oídio estimada na quinta (SO5) e sétima (SO7) folha de mamoeiro, Campos dos Goytacazes, 2014.

\begin{tabular}{lccc}
\hline & \multicolumn{3}{c}{ Efeitos genéticos aditivos preditos } \\
\cline { 2 - 4 } Progênies & IO & SO5 & SO7 \\
\hline PM1 & $-17,58$ & $-0,20$ & $-1,34$ \\
PM2 & $-0,34$ & $-0,11$ & 0,15 \\
PM3 & 0,88 & $-0,01$ & 0,21 \\
PM4 & $-0,06$ & 0,13 & 0,59 \\
PM5 & 5,60 & 0,03 & $-0,34$ \\
PM6 & $-4,51$ & $-0,15$ & $-0,46$ \\
PM7 & 2,42 & $-0,01$ & $-0,56$ \\
PM8 & $-4,42$ & $-0,12$ & $-0,88$ \\
PM9 & 3,54 & 0,01 & $-0,16$ \\
PM10 & 6,94 & $-0,04$ & 0,74 \\
PM11 & $-1,61$ & $-1,16$ \\
PM12 & $-10,15$ & $-0,11$ & $-1,08$ \\
PM13 & 6,13 & 0,41 & 0,84 \\
PM14 & 3,70 & $-0,08$ & $-0,79$ \\
PM15 & $-2,36$ & $-0,10$ & $-0,83$ \\
PM16 & $-7,39$ & 0,01 & 0,81 \\
PM17 & 1,73 & $-0,18$ & $-0,64$ \\
PM18 & 2,79 & $-0,06$ & 1,08 \\
PM19 & 2,21 & 0,01 & 0,17 \\
PM20 & 12,46 & 0,70 & 3,64 \\
\hline
\end{tabular}


(14), outra estatística comumente calculada no contexto da avaliação genotípica é o coeficiente de variação relativa $(\mathrm{CVr}=\mathrm{CVg} / \mathrm{CVe})$. Fixando-se o número de repetições (= quatro), a magnitude de $\mathrm{CVr}$ pode ser utilizada para inferir sobre a acurácia e a precisão na avaliação genotípica. Pelo exposto, considerando a magnitude do CVr, bem como a tabela apresentada por Resende \& Duarte (15), foram identificados valores de acurácia variando de 71 a $85 \%$, corroborando as estimativas obtidas anteriormente.

Pelos resultados, constatou-se haver variabilidade na população em estudo, o que permite a identificação de genitores que podem contribuir para o aumento e, ou diminuição da incidência e severidade de oídio em folha, denotando assim em possibilidade de seleção de progênies resistentes. Vivas et al. (18) avaliando o ciclo anterior das progênies em estudo, identificaram progênies com baixos valores de severidade de pinta-preta em folha. Em outro estudo conduzido ainda no ciclo anterior, Vivas et al. (22) aventaram a possiblidade de se obter plantas com potencial para a redução, tanto da pinta-preta, quanto para mancha-de-phoma, ratificando, assim, o grande potencial dos genótipos dióicos como portadores de genes de resistência a doenças $(7,18,21$, 22). No entanto, as progênies dióicas não haviam sido avaliadas para a resistência a oídio.

Analisando os dados das estimativas da contribuição relativa de cada genitor para a formação da próxima geração, obtidas via modelagem mista, observa-se que as progênies PMI1, PMI2, PMI4, PMI6, PMI8, PMI11, PMI12, PMI15, PMI16 apresentam potencial para redução da incidência de oídio em folha, enquanto que as PMI1, PMI6, PMI7, PMI8, PMI11, PMI12, PMI14, PMI15 e, PMI17, apresentam potencial para redução da severidade de oídio em folha (Tabela 2). Pelos resultados obtidos, aventa-se a possibilidade de redução da intensidade de oídio em progênies de mamoeiro, com destaque para as progênies PMI1, PMI6, PMI8, PMI11, PMI12 e PMI15 que apresentam potencial para redução tanto da incidência quanto da severidade de oídio em folha. Considerando que a progênies avaliadas foram derivadas de genitores com elevado potencial para redução da intensidade de pintapreta e mancha-de-phoma $(18,21,22)$, acredita-se que as progênies PMI1, PMI6, PMI8, PMI11, PMI12 e PMI15 apresentem potencial para redução a múltiplas doenças, o que será reavaliado nos trabalhos subsequentes.

\section{REFERÊNCIAS}

1. Barbieri, R.L.; Leite, D.L.; Choer, E.; Sinigaglia, C. Divergência genética entre populações de cebola com base em marcadores morfológicos. Ciência Rural, Santa Maria, v.35, n.2, p.303-306, 2005.

2 Cruz, C.D.; Carneiro, P.S.C. Modelos biométricos aplicados ao melhoramento genético. 2.ed. Viçosa: UFV, v.2. 2006. 586p.

3. Cruz, C.D. GENES - a software package for analysis in experimental statistics and quantitative genetics. Acta Scientiarum Agronomy, Maringá, v.35, n.3, p.271-276, 2013

4. Dantas, J.L.L. Cultivares. In: Trindade, A.V. (Ed.). Mamão: produção: aspectos técnicos. Brasília, DF: Embrapa Comunicação para Transferência de Tecnologia, 2000. (Frutas do Brasil, 3).

5. Fidelis, R.R.; Miranda, G.V.; Faluba, J.S. Capacidade de combinação de populações de milho tropicais sob estresse de baixo nitrogênio. Bioscience Journal, Uberlândia, v.26, n.3, p.358-366, 2010.

6. Liberato, J.R.; Barreto R.W.; Louro R.P. Streptopodium caricae sp.nov., whith a discussion on powdery mildew on papaya and an emended description of the genus Streptopodium and of Oidium caricae. Mycology Research, Cambridge, v.108, n.10, p.1185-1194, 2004.
7. Medeiros, L.A.M.; Balardin, R.S.; Costa, I.F.D.; Gulart, C.A.; Lenz, G. Reação de germoplasma crioulo de feijoeiro (Phaseolus vulgaris L.) a Colletotrichum lindemuthianum. Tropical Plant Pathology, Brasília, DF, v.33, n.4, p.273-280. 2008.

8. Neitzke, R.S.; Barbieri, R.L.; Heiden, G.; Büttow, M.V.; Oliveira, C.S.; Corrêa, L.B.; Schwengber, J.E.; Carvalho, F.I.F. Caracterização morfológica e dissimilaridade genética entre variedades crioulas de melão. Horticultura Brasileira, Brasília, DF, v.27, n.4, p.534-538, 2009.

9. Oliveira, E.J.; Amorim, V.B.O.; Matos, E.L.S.; Costa, J.L.; Castellen, M.S.; Pádua, J.G.; Dantas, J.L.L. Polymorphism of microsatellite markers in papaya (Carica papaya L.). Plant Molecular Biology Reporter, New York, v.28, n.3, p.519-530, 2010.

10. Oliveira, E.J.; Costa, J.L.; Santos, L.F.; Carvalho, F.M.; Silva, A.S.; Dantas, J.L.L. Caracterização molecular de genótipos de mamoeiro com uso de marcadores do tipo AFLP. Revista Brasileira de Fruticultura, Jaboticabal, v.33, n.3, p.848-858, 2011.

11. Oliveira, E.J.; Fraife Filho, G.A.; Freitas, J.P.X.; Dantas, J.L.L.; Resende, M.D.V. Plant selection in F2 segregating populations of papaya from commercial hybrids. Crop Breeding and Applied Biotechnology, Viçosa, v.12, n.3, p.191-198, 2012.

12. Pinto, F.O.; Luz, L.N.; Pereira, M.G.; Cardoso, D.L.; Ramos, H.C.C. Metodologia dos modelos mistos para seleção combinada em progênies segregantes de mamoeiro. Revista Brasileira de Ciências Agrárias, Recife, v.8, n.2, p.211-217, 2013.

13. Resende, M.D.V. O software Selegen Reml/Blup. Campo Grande: Embrapa Gado de Corte, 2006. 299p. (Documentos Embrapa Gado de Corte).

14. Resende, M.D.V. Matemática e estatística na análise de experimentos e no melhoramento genético. Embrapa Florestas: Colombo, 2007. 561p.

15. Resende, M.D.V.; Duarte, J.B. Precisão e controle de qualidade em experimentos de avaliação de cultivares. Pesquisa Agropecuária Tropical, Goiânia, v.37, n.3, p.182-194, 2007.

16. Santos, P.H.D.; Vivas, M.; Silveira, S.F.; Silva, J.M.; Terra, C.E.P.S. Elaboração e validação de escala diagramática para avaliação da severidade de oídio em folhas de mamoeiro. Summa Phytopathologica, Botucatu, v.37, n.4, p.215-217, 2011

17. Tatagiba, J.T.; Liberato, J.R.; Zambolim, L.; Costa, H.; Ventura, J.A. Controle químico do oídio do mamoeiro. Fitopatologia Brasileira, Brasília, DF, v.27, n.2, p.219-222, 2002.

18. Vivas, M.; Silveira, S.F.; Vivas, J.M.S.; Pereira, M.G. Patometria, parâmetros genéticos e reação de progênies de mamoeiro à Pinta-preta. Bragantia, Campinas, v.71, n.2, p.235-238, 2012.

19. Vivas, M.; Silveira, S.F.; Cardoso, D.L.; Pereira, M.G.; Vivas, J.M.S.; Ferreguetti, G.A. Capacidade combinatória em mamoeiro para resistência a oídio. Bragantia, Campinas, v.71, n.4, p.455-459, 2012.

20. Vivas, M.; Silveira, S.F.; Terra, C.E.P.S.; Pereira, M.G. Reação de germoplasma e híbridos de mamoeiro à mancha-de-phoma (Phoma caricae-papayae) em condições de campo. Tropical Plant Pathology, Brasília, DF, v.35, n. 5 , p.323-328, 2010

21. Vivas, M.; Silveira, S.F.; Vivas, J.M.S.; Pereira, M.G. Predição de ganhos genéticos e seleção de progênies de mamoeiro para resistência à pinta-preta. Tropical Plant Pathology, Brasília, DF, v.38, n.2, p.142-148, 2013.

22. Vivas, M.; Silveira, S.F.; Vivas, J.M.S.; Viana, A.P.; Amaral Junior, A.T.; Pereira, M. G. Seleção de progênies femininas de mamoeiro para resistência a mancha-de-phoma via modelos mistos. Bragantia, Campinas, v.73, n.4, p.446-450, 2014.

23. Vivas, M.; Silveira, S.F.; Viana, A.P.; Amaral Junior, A.T.; Cardoso, D.L.; Pereira, M.G. Efficiency of circulant diallels via mixed models in the selection of papaya genotypes resistant to foliar fungal diseases. Genetics and Molecular Research, Ribeirão Preto, v.13, n.3, p.4797-4804, 2014.

24. Vivas, M.; Silveira, S.F.; Viana, A.P.; Amaral Junior, A.T.; Ferreguetti, G.A.; Pereira, M.G. Resistance to multiple foliar diseases in papaya genotypes in Brazil. Crop Protection, Guildford, v.71, p.138-143, 2015. 